\title{
Confucius Institute and the Development of Chinese Language Teaching in Cameroon
}

\author{
Jean Gonondo \\ Higher Teachers' Training College, University of Maroua (Cameroon), BP 55 Maroua \\ gonondojean@163.com
}

\begin{abstract}
Cameroon and China have been cooperating and exchanging in several areas for a long time. In the educational sector, the Confucius Institute plays an important and 'unique' role in the materialisation of the educational and cultural exchange between the two countries. In recent years, the institute is experiencing a resurgence of interest in Chinese language and culture among young Cameroonians. The number of learners enrolled in the Confucius Institute is increasing, and the realisations of the Institute are obvious, it includes the grant of scholarships to study in China, the training programmes for local Chinese teachers and the opportunities of work for graduated students. Nevertheless, despite the success and various realisations of the Confucius Institute in Cameroon, some issues influencing the performance of this institution and the quality of the cooperation need to be addressed. It remains necessary to conduct some reforms on the management of the cooperation to attend an effective and successful educational and cultural exchange and mutual understanding.
\end{abstract}

Keywords: Confucius Institute, Cameroon, China, Educational and Cultural exchange, Chinese teaching.

DOI: $10.7176 / \mathrm{JEP} / 12-3-05$

Publication date: January $31^{\text {st }} 2021$

\section{Background}

Africa and China educational cooperation has a long history and dates back to the 1950s. It is usually referred as a 'South-South development cooperation' (Niu, 2013, p. 31). The 'Chinese model' of cooperation with African countries is distinctive from other foreign investment and aid (Sautman \& Hairong, 2007, p. 75). The cooperation policies have gone through different stages, namely the period of political alignments (1950-1989), the period of Africa as a source of political support (1989-2000), and the period of increasing economic relationship (2000present) (Nordtveit, 2011, pp. 100-102). To promote this relationship, the Forum on China-Africa Cooperation (FOCAC) was set up in 2000 and constitutes an important platform and mechanism for the conduct of collective dialogue, the exchanging of experiences, and the enhancement of mutual trust and cooperation (Shelton \& Paruk, 2008). In the educational sector, the cooperation focuses on mutual understanding and friendship, mutual benefits and common development, African countries capabilities, practical actions (Niu, 2013, pp. 34-35). The SinoAfrican educational cooperation covers a wide range of programmes such as human resources cooperation, the Chinese language teaching, the granting of Chinese Government Scholarship (CSC), School construction projects, and higher education cooperation (Niu, 2013, pp. 37-42).

Cameroon is among the countries which have relatively extended cooperation with China (Nordtveit, 2011, p. 99). The Cameroon-China cooperation dates back to 1970 with the establishment of diplomatic relations between the two countries. This cooperation has known a significant development since 1990 and covers the political, economic, and educational sectors (Cabestan, 2015, p. 67). The two countries have signed some strategic agreements in the sector of trade in 1972, reciprocal protection and promotion of investments in 1997, and also for economic and commercial cooperation in 2002 (Jansson, 2009, p. 4). China is one of Cameroon's 'key economic and political partners' (Cabestan, 2015, p. 87). In the educational sector, China constitutes an important partner for Cameroon with relatively extended cooperation. China provides some educational support such as lab equipment, scholarship provisions, and the establishment of the Mandarin language teaching centre transformed into the Confucius Institute in 2007 (Jansson, 2009, p. 7). The Confucius Institute plays an important role in the educational and cultural exchange between the two countries.

The Confucius Institute considered as the largest international educational cooperation project in human history and the largest internationalisation project in China aimed to promote the teaching of Chinese language, and the popularisation of the Chinese culture around the world (J. Li \& Xiaohong, 2016). It constitutes a 'tool of public diplomacy' for Chinese foreign affairs (Hartig, 2016). The Confucius Institute is also considered as a 'form of cultural diplomacy that is state-sponsored and university piloted, a joint effort to gain China a more sympathetic global reception' (Pan, 2013, p. 22). Up to now, 541 Confucius Institutes and 1170 Confucius Classrooms have been established in 162 countries (regions) around the world since 2004. In Africa, 61 Confucius Institutes and 48 Confucius Classrooms were set in 46 countries (Hanban, 2021).

In Cameroon, the Confucius Institute was launched on $9^{\text {th }}$ November 2007 and replaced the former Chinese Language Training Centre established since 1996. It constitutes the third Confucius Institute in Africa after the Confucius Institute at the University of Nairobi (Kenya) launched on the $19^{\text {th }}$ December 2005, and the Confucius 
Institute at the University of Zimbabwe established on the $2^{\text {nd }}$ November (Gonondo, 2018, pp. 87-88). The Confucius Institute at the University of Yaoundé 2 is currently jointly managed by Zhejiang Normal University and the University of Yaoundé 2. It focuses on the training for the preparation of the "Chinese Bridge" competition, the training for the Chinese proficiency test, the Chinese language and culture teaching. The Confucius Institute at the University of Yaoundé 2 constitutes a platform for the teaching of Chinese language and culture for Cameroon and neighbouring countries. This institute which trains Chinese language talents also constitutes a platform for promoting economic, educational and cultural exchanges between the two countries ${ }^{1}$.

\section{Literature Review}

\subsection{China Educational Support to Cameroon}

The Chinese educational support in Cameroon includes language training programmes through different centres of the Confucius Institutes, scholarships for training in China and human resource building, construction of schools, higher education cooperation (Nordtveit, 2011, pp. 102-105). The Chinese government gives a "high symbolic value" to the scholarship granted to African countries (Haugen, 2013, p. 315). Attracting Africans to pursue their studies in China has a strategic significance: it is beneficial to enhance the cultural exchanges between China and African countries; it promotes the construction of a "China-Africa community with a shared future"; it promotes China-Africa economic cooperation; it helps also to increase the international influence of Chinese universities (G. Huang \& Zhuo, 2019). The scholarship provision represents the earliest form of educational cooperation between China and African Countries, and it is on the FOCAC agenda (Ehizuelen Omoruyi et al., 2017, p. 10). China began the scholarship cooperation with Cameroon since 1995, and nowadays China constitutes its first scholarship donor (Nordtveit, 2011, p. 103). The number of scholarship application is growing every year. Cameroonians benefit from different types of scholarships including the bilateral scholarship (managed by the Ministry of higher education and the Chinese embassy), and the Confucius institute scholarship (Chinese language training scholarships) (Ehizuelen Omoruyi et al., 2017, p. 13). Besides the two above well-known types of scholarship, there are also the CSC (China Scholarship Council) scholarship, the MOFCOM (Ministry of Commerce) Scholarship, the provincial scholarship (for example, Zhejiang Province Scholarship), City Scholarship (for example, Jinhua City Scholarship), University scholarship (for example, Zhejiang Normal University Scholarship), outstanding students' scholarship, silk road special scholarship (ZJNU, 2020). Even though the support is limited with some types of scholarships (Provincial, City, University scholarship, etc.), we can notice that recently, more and more Cameroonians are enrolled in the Chinese universities under these partial scholarships.

Concerning human resource development cooperation, China offers a range of short-term training courses in many areas for some African countries. The training courses cover the sector of politics, education, agriculture, environmental protection, public policies, fishing industries, medicinal plants, economy, information technology and journalism (Niu, 2013, p. 37). This training program aimed to train 30,000 from Africa and Latin America. Every year the Chinese authorities provide short-term training for Cameroonian technicians and civil servants. The training takes between 6 months and a year for the technicians, and 2-3 weeks for the civil servants (Nordtveit, 2011, p. 104)

The educational support of China to Cameroon also includes several donations such as the lab equipment donated to the University of Yaoundé I, and the construction of two schools in Nanga and Guider (Jansson, 2009, pp. 7-8). The Chinese government completed the construction of three primary schools in 2009 (Ehizuelen Omoruyi et al., 2017, p. 13).

\subsection{Chinese Language and Culture Training Programmes in Cameroon}

The key activity of the Confucius Institute is Chinese learning and teaching (L. M. Li, 2019, p. 50). The training programs includes "Chinese cultural training courses, and cultural activities such as Taijiquan (martial art), calligraphy, paper-cutting, Chinese painting, traditional Chinese opera and skills of traditional Chinese massaging', (Ehizuelen Omoruyi et al., 2017, p. 12). The Chinese training programme focuses on resource building and cultural sensitizing about China (Nordtveit, 2011, p. 102).

The first Chinese language training institution in Africa was established in Cameroon by the Chinese National Council of Education in 1996 (Niu, 2013, p. 39). This language training centre emerged into the Confucius Institute in 2007 and focuses on Chinese language and culture teaching and spreading. The language teaching is usually followed by the organisation of some colourful events about Chinese culture. The Chinese martial art, songs and music, folk instruments, folk dancing, traditional Chinese opera, Chinese chess, the art of paper-cut, Chinese knot, Chinese calligraphy, Chinese paintings, tea art are some of the cultural content taught by the Confucius Institute in Cameroon (Y. Huang, 2019; Liu \& Zhao, 2019). The growing interest for the Chinese language is perceptible through the opening of some annexe of the Confucius Institute at the University of Maroua, and the University of Douala (Nordtveit, 2011, p. 103).

\footnotetext{
${ }^{1}$ http://hb.zjnu.edu.cn/447/list.htm
} 
Considering the availability of opportunities (employability within the established Chinese companies), the interest in learning the Chinese language is growing. In 2016, around 10,000 persons were engaged in Chinese learning (As noted in Ehizuelen Omoruyi et al., 2017, pp. 11-12).

\section{Methodology}

This study employed a qualitative research method, with the use of observation and documents review techniques. The qualitative research method considered that 'reality is subjective, and the social world has no objective existence independent of individuals' views, perception and behaviour' (Basit, 2010, p. 16).

The current study focuses on the analysis of some documents about the role of the Confucius Institute in the development and promotion of the Chinese language teaching in Cameroon. The documents sources are essential because they enable to have a historical comprehension of the topic, to track the change and development, to have some descriptive information about the topic, to verify emerging hypotheses, and advance new categories and hypotheses (Merriam \& Tisdell, 2016, p. 182).

Also, the observation constituted a significant tool in the data collection process. The observation enables to gather 'first hand' data, from 'naturally occurring social situations' (As cited in Cohen et al., 2018, p. 542). Johnson \& Christensen (2014) defined observation as the watching of behavioural patterns of people in certain situations to obtain information about the phenomenon of interest (p.315). As a former student majoring in Chinese, the author has been taught at higher teachers' training college (hereafter HTTC) of the University of Maroua by the Chinese teachers from the Confucius Institute, and later worked as a Chinese teacher in the same institution. During the studies and teaching period, the author has been in contact with the Confucius Institute and has observed and experienced some facts.

In this research, the author proceeded through a descriptive and critical analysis of the documents and observation notes using some themes such as "Chinese language and culture training", "Confucius institute in Cameroon", "cultural disparities", and "managerial issues".

\section{Findings and Discussion}

\subsection{Confucius Institute Realisations in Cameroon}

In recent years, the Confucius Institute is experiencing a surge of interest in Chinese language and culture among young Cameroonians. The number of students enrolled by the Confucius Institute is increasing each year. The institute, which started with few training classes, has currently some branches in Douala, Yaoundé and Maroua. The Confucius Institute students include university students, government officials, and also some representatives of the private sectors (Jansson, 2009, p. 7). The branch of Maroua is involved in Chinese language and culture teaching at the HTTC and the Faculty of Letters and Human Sciences of the University of Maroua. The students of the HTTC are trained to be the future local Chinese language and civilisations teachers in government secondary schools. While students from the Faculty of Letters and Human Sciences after getting their Bachelor degree can pursue their postgraduate studies or directly look for employment. Some of them are working as Chinese teachers in private schools, some as a temporary Chinese teacher in the public schools and some are working as interpreters in the various Chinese companies in the country. Based on their performance, some Cameroonians are employed to work with Chinese companies abroad. Some are working in Chad, Gabon, Central African Republic, Republic of the Congo, Togo, the Democratic Republic of the Congo, Ghana, Ivory Coast, Mauritania, Niger, France, etc.

This interest is also noticeable at the highest level of the State sphere as the Cameroonian Government has, since 2012, introduced the Chinese language among the foreign languages taught in secondary schools alongside Arabic, German, Spanish, Italian, Latin.... For this purpose, the University of Maroua, one of the eight state universities, offers the Chinese language as a major respectively in the Higher Teachers' Training College (since 2008) and the Faculty of Letters and Human Sciences (since 2014). With the support of the Confucius Institute, the HTTC at the UMa is the first and the only institution across the whole Central and West Africa to train the local Chinese teachers. After the introduction of the Chinese language to the Cameroonian educational system, many private primary schools, secondary schools and higher education institutions have also introduced the Chinese language as a subject in their curriculum.

In addition to language training, the Confucius Institute holds many cultural activities such as exhibitions, concerts, films screenings, and lectures (Niu, 2013, p. 40). Also, the Chinese bridge competition is a regular activity organised at all Confucius Institutes around the world, and which semifinals and final are held in China, and the winner receive the title of 'Chinese Language Envoy' and obtain scholarships to study in China (Niu, 2013, p. 40). According to the Confucius Institute data, more than twenty Cameroonian students have been in China to participate in the international Chinese bridge competition. In May 2019, the student Hulda Grace from the University of Maroua won the Cameroon region of the Chinese bridge competition for foreign college students and went to China to participate in the International Chinese bridge competition (Xinhua Net, 2019).

In 2019 the Confucius Institute has established the first local Chinese teachers training base in Africa and the Chinese language teachers' training centre in Central and Western African countries. The centre has as main 
objective to improve the teaching skills for local Chinese teachers. Recently, many training programmes both at the regional and national level have been jointly organised by the Confucius Institute, the Higher Teachers' Training College at the University of Maroua and the Ministry of Secondary Education. Before the current covid19 pandemic situation, Zhejiang Normal University organised every year a training programme. During these international training programmes many Cameroonian local Chinese teachers to be trained during some weeks in China. Due to the covid-19 pandemic problem, the third "Local Chinese teachers training" has been held online (August 29-30, 2020). During the training, many lecturers from the Confucius Institute and the University of Maroua have shared their experiences on various aspects of the Chinese teaching, including the Chinese characters, the Chinese culture, the Chinese phonetics, the Chinese vocabulary and grammar, a comprehensive Chinese lesson teaching methods, and the online teaching skills. More than a hundred participants principally from Cameroon took part in the online training. The fourth edition of the local Chinese teachers training will be held from $16^{\text {th }}$ to $17^{\text {th }}$ January 2021. The targeted participants are the local Chinese teachers from Cameroon and other central and western African countries. From the two hundred and fifty awaited participants, one hundred and twenty-two local Chinese teachers from Cameroon, Mauritania, Mali, Togo, Sierra Leone, Nigeria, Angola, Rwanda, Burundi, South Africa and Zambia have already subscribed for the training.

The Confucius Institute offers many opportunities to Cameroonian students such as short-term and long-term scholarship to pursue their language training in China. Some of the students trained in this institute work later as a translator for Chinese companies and medical team presents in Cameroon (Jansson, 2009, p. 7).

\subsection{Challenges}

The challenges encountered by both parts are much more related to the academic environment disparities and managerial issues.

4.2.1 Academic Culture Disparities

Each higher education institution is characterised by a particular academic culture. The academic culture is considered as the special culture created with the common beliefs, common academic responsibilities, and common academic norms and regulations developed within the higher education institutions (Shen \& Tian, 2012, p. 61). The special status of the Confucius Institute raises some issues given to the joint management system and the difference in academic culture.

Due to the difference of academic environment between the Chinese partner university and the Cameroonian host university, some issues related to human resources management reappear. Most of the Chinese teachers sent by the Chinese partner university are Master students, some are even Bachelor students (Zhang, 2015, p. 23); while the academic culture of Cameroonian universities is quite different, it requires at least a Master degree to teach at the University. This situation creates some dissatisfaction on both sides. The Chinese side is facing some challenges when the Cameroonian partner does not perform in time its responsibilities in providing some facilities (infrastructural, financial, materials, etc.).

\subsubsection{Managerial Issues}

As noted by Li (2019), three institutional stakeholders, namely Hanban, a Chinese partner university, and the local host university are involved in the management of most Confucius institutes. These stakeholders are motivated by different intentions and interests. Indeed, Hanban which is the Confucius Institute headquarter aims at promoting the Chinese language (specifically Putonghua and simplified Chinese, and international Chinese). While the Chinese partner universities are expected to contribute to the implementation of this important national strategy (promotion of international Chinese), they are determining the degree of their involvement. As concern the local host universities, the intentions are usually quite different from those of the Chinese partner. The local host universities are usually pursuing internationalization (L. M. Li, 2019, pp. 73-78). The financial resources arise from Hanban (primary cash funder), Chinese partner universities (mostly expertise in designing and delivering Chinese language courses), and local host universities (limited contributions). Generally, the Chinese partner universities provide the co-directors and teachers; while local host universities provide the local personnel, rooms and facilities (Hartig, 2011, p. 60). The joint-venture nature of the Confucius Institute constitutes an attractive model for all partner institutions, even if their approach and level of commitments depend on their approaches and intentions (L. M. Li, 2019, pp. 73-94).

Firstly, the Confucius Institute has its organisational planning according to the Chinese system and calendar, which is quite different from the Cameroonian system and academic calendar. This causes an overlapping of programmes. Secondly, discussions conducted with some Cameroonian officials from the hosting universities indicate that they feel left out in crucial operational procedures and decision making processes hindering effective coordination. Finally, lack of cooperation was profound in the attribution of scholarship to the students of Higher Teacher's Training College who are intended to teach the Chinese language in the various public high schools across the country. 


\section{Conclusion}

The issue regarding the quality enhancement of the educational and cultural exchange to attain effective and efficient human resource cooperation remains a major preoccupation in Africa-China relations. A tentative of solution could be the establishment of some joint-educational and cultural programmes. The Confucius Institute should serve as bidirectional and pluralising cultural bridges, not just work to disseminate the Chinese culture, as noted by Li Yuanchao during the Joint Conference of Confucius Institutes in Africa on June 24, 2014. For more effectiveness, the development of Chinese language teaching and learning by the Confucius Institute should go through more efficient allocation and global coordination mechanisms. The Confucius Institute constitutes a window through which some Cameroonians can learn more about China and Chinese culture; however, this Institution has to provide more effort concerning the mutual understanding of Cameroon and China.

\section{References}

Basit, T. N. (2010). Conducting Research in Educational Contexts. Continuum International Publishing Group. Cabestan, J.-P. (2015). China-Cameroon relations: Fortunes and limits of an old political complicity. South African Journal of International Affairs, 22(1), 67-91. https://doi.org/10.1080/10220461.2015.1014930

Cohen, L., Manion, L., \& Morrison, K. (2018). Research Methods in Education (8th ed.). Routledge Taylor and Francis Group.

Ehizuelen Omoruyi, M. M., Yao, J., ABAH Bidias, A. S., \& Mvuh, Z. (2017). China Enhancing Education Development in Africa: A Case Study of Cameroon. Research on Humanities and Social Sciences, 7(15), 819.

Gonondo, J. (2018). Research on China-Africa higher education cooperation and exchange: Practice and effects of the short-term seminars. Zhejiang Normal University.

Hanban. (2021). Confucius Hanban. http://www.hanban.org/confuciousinstitutes/node_10961.htm

Hartig, F. (2011). Confucius Institutes and the Rise of China. Journal of Chinese Political Science, 17, 53-76. https://doi.org/DOI 10.1007/s11366-011-9178-7

Hartig, F. (2016). Chinese Public Diplomacy: The Rise of the Confucius Institute. Routledge.

Haugen, H. Ø. (2013). China's recruitment of African university students: Policy efficacy and unintended outcomes. Globalisation, Societies and Education, 11(3), 315-334. https://doi.org/10.1080/14767724.2012.750492

Huang, G., \& Zhuo, X. (2019). A survey of scholarship application for African universities Chinese majors students: Taking students majoring in Chinese at the University of Maroua in Cameroon as an example [非 洲汉语专业大学生奖学金申请调查_喀麦隆马鲁阿大学汉语专业学生为例]. Heilongjiang Jiaoyu·lilun Yu Shijian, 10, 60-62.

Huang, Y. (2019). Feizhou Kongzi Xueyuan wenhua ke jiaoxue de xianzhuang, wenti ji duice_—Yi Kamailong Yawende di er daxue Kongzi Xueyuan weili [The current situation, problems and countermeasures of cultural teaching in African Confucius Institute: The case of Cameroon Confucius Institute at the University of Yaounde II]. wenjiao ziliao, 3, 73-76.

Jansson, J. (2009). Patterns of Chinese Investment, Aid and Trade in Central Africa (Cameroon, the DRC and Gabon) (p. 59) [Paper]. Centre for Chinese Studies, University of Stellenbosch.

Johnson, R. B., \& Christensen, L. (2014). Educational research: Quantitative, qualitative, and mixed approaches (5th ed.). SAGE Publications.

Li, J., \& Xiaohong, T. (2016). A Global Experiment in the Internationalization of Chinese Universities: Models, Experiences, Policies, and Prospects of the Confucius Institutes' First Decade. Chinese Education \& Society, 49(6), 411-424. https://doi.org/10.1080/10611932.2016.1262682

Li, L. M. (2019). Language management and its impact: The policies and practices of Confucius Institutes. Routledge.

Liu, Q., \& Zhao, Y. (2019). Feizhou Kongzi Xueyuan wenhua chuanbo shijian yanjiu—Yi Kamailong Yaerda Kongyuan weili [Research on Cultural-Communication Practice in Confucius Institute of AfricaConfucius Institute of the University of Yaounde II in Cameroon for Example]. Journal of Chuxiong Normal University, 34(6), 075-080.

Merriam, S. B., \& Tisdell, E. J. (2016). Qualitative Research: A Guide to Design and Implementation. JosseyBass.

Niu, C. (2013). China's educational cooperation with Africa: Toward new strategic partnerships. Asian Education and Development Studies, 3(1), 31-45. https://doi.org/10.1108/AEDS-09-2013-0057

Nordtveit, B. H. (2011). An emerging donor in education and development: A case study of China in Cameroon. International Journal of Educational Development, 31(2), 99-108. https://doi.org/10.1016/j.ijedudev.2010.01.004

Pan, S. (2013). Confucius Institute project: China's cultural diplomacy and soft power projection. Asian Education 
and Development Studies, 2(1), 22-33. https://doi.org/10.1108/20463161311297608

Sautman, B., \& Hairong, Y. (2007). Friends and Interests: China's Distinctive Links with Africa. African Studies Review, 50(3), 75-114. https://doi.org/10.1353/arw.2008.0014

Shelton, G., \& Paruk, F. (2008). The Forum on China- Africa cooperation: A strategic opportunity. Institute for Security Studies.

Shen, X., \& Tian, X. (2012). Academic Culture and Campus Culture of Universities. Higher Education Studies, 2(2). https://doi.org/10.5539/hes.v2n2p61

Xinhua Net. (2019). The 18th Chinese Bridge Competition for University students, the Cameroon region competition ended [第 18 届大学生“汉语桥”喀麦隆赛区比赛落幕]. Chinese Bridge. http://bridge.chinese.cn/c18/opr/195/195_6461_1.html

Zhang, P. (2015). Kamailong Kongzi Xueyuan hanyu jiaoxue shizi zhuangkuang yanjiu [Research on Chinese teachers' conditions at Confucius Institute in Cameroon]. Zhejiang Normal University.

ZJNU. (2020). Zhejiang shifan daxue 2020 nian guoji xuesheng jiangxuejin xiangmu [Zhejiang Normal University 2020 international students Scholarship $\quad$ Program]. http://iso.zjnu.edu.cn/zjsfdx2018gjxsjxjxm/list.htm 